\section{Pharmacists are the gatekeepers to the use of antimicrobials}

\author{
Phil Wiffen
}

Who says? The recent EU guidelines for the prudent use of antimicrobials ${ }^{1}$ in human health has exactly this statement. It is rare to find such a strong endorsement of pharmacists' roles and this presents both a challenge and an opportunity. The guidelines go on to state that pharmacists can act (or should!) as an important source of advice and information for patients and prescribers on safe, rational and effective use. This is explicitly described with nine suggestions including adherence, storage and disposal.

The guideline recognises that certain things need to put into place including appropriate training to ensure the prudent use of antimicrobials and to help manage patient expectations. Could this be a helpful track in a future European Association of Hospital Pharmacists Congress? The guidance goes on to state that a pharmacist should (note: should) be a member of the antimicrobial stewardship team and working across disciplines as well as monitoring antimicrobial use.

For many, this will be business as usual where pharmacists' roles within this field are firmly established. Most hospital computer systems will provide the data for monitoring use of antimicrobials, but further analysis may need to be developed. There is scope for research and publication of good methods and sound wisdom.

For others, this is a great development opportunity and the guidelines should be used to obtain additional funding for such work.

Interestingly, there are some must dos (the guidelines are aimed at pharmacists

Correspondence to Professor Phil Wiffen, Pain Research Unit, Churchill Hospital, Oxford OX3 7LE, UK; phil.wiffen@ndcn.ox.ac.uk in both community and hospital settings). These include:

- Antimicrobials must be supplied on a prescription.

- Ensure the patient understands dose, duration and adherence issues.

- Promote appropriate disposal of leftover antimicrobials.

- Notify authorities of adverse events.

- Participate in promotional campaigns to promote the prudent use of antimicrobials.

- Provide advice to patient and professionals regarding contraindications, drug interactions and food-drug interactions.

Pharmacists need to rise to these challenges, and some of the must-do items seem to be lacking underpinning evidence. Little has been published on disposal, for example. It would be good to see existing policies on disposal of these agents if they exist.

Southern Europe has higher levels of antimicrobial resistance so the guidelines are even more important in that part of the world and pharmacists may well have a fiercer fight on their hands to implement the requirements.

So where do pharmacists find information to support the development of roles in antimicrobial stewardship? There is literature-largely from the USA, ${ }^{2}$ but it is still quite limited. A recent study by Broom et al from Australia, ${ }^{3}$ which used semistructured interviews with 19 pharmacists based in Queensland, regarding pharmacists' attitudes showed that the profession still has a long way to go in terms of involvement in antimicrobial management. The authors described pharmacists' attitudes as ambivalent due to three factors. First, they didn't see optimising antimicrobial use as a high priority; second, they saw prescribing antimicrobials as a medical responsibility; and third, they felt there were interprofessional and organisational barriers to the pharmacists' role.

These issues almost certainly exist in parts of Europe, but we cannot allow a world where antimicrobials become ineffective; that is unthinkable.

A view of the development of pharmacist services in the UK also provides a useful background. ${ }^{4}$ This paper might be a good place to start and has an extensive bibliography.

The European Commission guidelines are a call to arms. Pharmacists have an even stronger mandate to fight for their place in managing antimicrobial agents in hospitals, and action is needed to build the evidence base both to provide the underpinning evidence for the required roles and to prove that pharmacists can and will deliver improved use of antimicrobials in a cost effective and timely way.

\section{Competing interests None declared.}

Provenance and peer review Commissioned; internally peer reviewed.

(c) European Association of Hospital Pharmacists (unless otherwise stated in the text of the article) 2017. All rights reserved. No commercial use is permitted unless otherwise expressly granted.

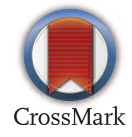

To cite Wiffen P. Eur J Hosp Pharm 2017;24:313.

Eur J Hosp Pharm 2017;24:313.

doi:10.1136/ejhpharm-2017-001420

\section{REFERENCES}

1 EU Guidelines for the prudent use of antimicrobials in human health, 2017. Commission notice 2017/C 212/01.

2 Heil EL, Kuti JL, Bearden DT, et al. The essential role of pharmacists in antimicrobial stewardship. Infect Control Hosp Epidemiol 2016;37:753-4.

3 Broom A, Broom J, Kirby E, et al. What role do pharmacists play in mediating antibiotic use in hospitals? A qualitative study. BMJ Open 2015;5:e008326

4 Gilchrist M, Wade P, Ashiru-Oredope D, et al. Antimicrobial stewardship from policy to practice: experiences from UK antimicrobial pharmacists. Infect Dis Ther 2015;4(Suppl 1):51-64. 